\title{
DANÇA NOS CICLOS DE ESCOLARIZAÇÃO: APROXIMAÇÕES TEÓRICAS
}

\author{
Gina GuimarÃes*
}

\section{RESUMO}

A proposta do texto é iniciar uma análise sobre o conteúdo Dança e os ciclos de escolarização, à luz de uma revisão bibliográfica. Buscaremos refletir acerca da sistematização do conhecimento a partir da referência teórica que mais bem organiza, no nosso entendimento, o trato pedagógico da Educação Física Escolar, uma proposta de Soares et al. (1992). Analisaremos, também, as propostas da dança na escola sugeridas por Marques (1999), Gehres (1996) e Xarez et al. (1992). Nosso objetivo é traçar uma reflexão acerca deste conteúdo numa abordagem que mais se aproxime da sistematização em ciclos de conhecimento, além de ampliá-la. Serão destacadas as possibilidades de conquistas e dificuldades.

PALAVRAS-CHAVE: Escola - Dança - Ciclos de sistematização do conhecimento.

\section{INTRODUÇÃO}

$\mathrm{O}$ campo teórico da Educação Física vem buscando superar sua atuação na escola a fim de estabelecer-se como disciplina curricular. Já nas décadas de 1970 e 1980 infinitas discussões tentavam criar um embasamento que proporcionasse à Educação Física atuar na escola como algo a mais que pura atividade física. Fazia-se necessário evitar que ela fosse utilizada apenas para manter níveis ótimos de aptidão física ou para combater o estresse das crianças em decorrência das altas horas de atividades na carteira da sala de aula.

Após anos e anos de estudos, vários teóricos procuraram contribuir com abordagens diversificadas sobre a Educação Física. Dentre estes, elegemos Pimenta \& Gonçalves, cuja proposta até então parece ser a mais clara e objetiva para o campo escolar. Sua proposta mostra-se mais determinada no que diz respeito ao modelo de sociedade, o qual requer uma escola "democrática, universal, gratuita, obrigatória, laica e unitária,

* Graduada em Educação Física pela ESEF/UPE, professora da rede particular de ensino. 
resultado de um projeto coletivo e adequada em relação aos seus equipamentos materiais e espaços físicos" (Pimenta \& Gonçalves, apud Soares et al., 1992, p. 23). Os autores destacam ainda o trato com o conhecimento, que nessa abordagem tem por princípios

a relevância social do conteúdo [...], a contemporaneidade do conteúdo [...], a adequação às possibilidades sociocognoscitivas do aluno [...], a simultaneidade dos conteúdos enquanto dados da realidade [...], a espiralidade da incorporação das referências do pensamento [...], e a provisoriedade do conhecimento. (p. 33)

Ou seja, a proposta busca lutar contra a

fragmentação, a estaticidade, a unilateralidade, a terminalidade, a linearidade e o etapismo [princípios da lógica seriada, e defender uma lógica dialética em que se observe] totalidade, movimento, mudança qualitativa e contradição. (p. 34)

Isso favorecia uma reflexão pedagógica ampliada cujos fundamentos seriam "a constatação, a interpretação, a compreensão e explicação da realidade social complexa e contraditória" (p. 28). Vale ressaltar que tal reflexão só seria possível a partir da sistematização do conhecimento com diferentes áreas e disciplinas, de modo a formular uma síntese.

Com relação à sistematização do conhecimento Gehres (1996, p. 27) insiste em afirmar que ela não ocorre apenas no campo racional e cognitivo, "mas também no campo do vivido e sentido".

Soares et al. (1992, p. 102) diz que o objeto de estudo da Educação Física Escolar é a "expressão corporal como linguagem" e elege como temas para sua prática pedagógica no ambiente da escola as "atividades expressivas corporais como: jogo, esporte, dança, ginástica e luta" (p. 50).

Para a organização curricular, a proposta elege o sistema de ciclos de sistematização do conhecimento, e dentre estes a dança. Aproximamo-nos desta no que diz respeito à disciplina Educação Física por compreender que seus pressupostos estão diretamente ligados à proposta dos ciclos, que têm 
como raiz a organização do espaço e do tempo escolar e da prática pedagógica sem recortar e separar - o que empobrece a aprendizagem -, e buscam uma visão de flexibilidade e a articulação, como tentativa de atingir a complexidade das dimensões do humano e da cultura. (Recife, 2002, p. 30)

Os ciclos apresentam como princípios a igualdade de acesso ao conhecimento, o reconhecimento das diferenças e a integralidade e autonomia dos alunos. Cabe ao professor fazer parte da teia que entrelaça esses princípios, que compreendem a educação como "ação integrada", dentro das interferências de um contexto sociocultural. Exige-se dele

aprofundamento teórico em várias áreas do conhecimento; revisão metodológica das sequiências didáticas [...]; ação emancipatória e transformadora; reflexão pessoal de posturas e [...] trabalho compartilhado em todas as ações do processo educativo. (p. 32)

Para Soares et al. (1992), cuja proposta tem seu ponto central na estrutura cíclica, o princípio básico do trato com o conhecimento está na ampliação do pensamento do aluno de maneira espiralada, de modo a atingir desde sua constatação da realidade, passando pela interpretação e compreensão até explicar esse pensamento. Quando o conhecimento não é organizado por etapas, o aluno vivencia diferentes ciclos ao mesmo tempo, de acordo com o conteúdo tratado e com sua experiência anterior.

$\mathrm{Na}$ tentativa de melhor estruturar os ciclos de escolarização os autores propõem a seguinte organização:

I ciclo - pré-escola à $3^{\text {a }}$ série: ciclo de organização da identidade dos dados da realidade;

II ciclo $-4^{\mathrm{a}}$ à $6^{\mathrm{a}}$ série: ciclo de iniciação à sistematização do conhecimento;

III ciclo $-7^{\mathrm{a}}$ à $8^{\mathrm{a}}$ série: ciclo de ampliação da sistematização do conhecimento;

IV ciclo $-1^{\mathrm{a}}, 2^{\mathrm{a}}$ e $3^{\mathrm{a}}$ séries do ensino médio: ciclo de aprofundamento da sistematização do conhecimento. 


\section{A DANÇA NO PROCESSO DE ESCOLARIZAÇÃO BÁSICA}

O conteúdo "dança" participa do conjunto das atividades expressivas corporais eleitas para o trabalho pedagógico da Educação Física na proposta de Soares et al. (1992). No entanto o trabalho com a dança em sala de aula carece de elementos mais específicos até porque ela tem vida própria fora do campo da Educação Física. Por isso aqui apresentaremos estudos da área da dança que buscam organizar conteúdos mais detalhados para seu trabalho na escola e que se aproximam da diretriz político-pedagógica desses autores.

Existem propostas sobre a dança na escola que se apropriam do conhecimento produzido sobre ela no campo da arte. Tais propostas podem ser utilizadas nas aulas de Educação Física, fazendo-se necessário, para tanto, que a dança estabeleça nexos de semelhanças e diferenças com os demais conteúdos tratados na disciplina. Antes de apresentar essas propostas, vale esclarecer que entendemos a dança como gestos virtuais oriundos de sentimentos imaginados, sendo que o seu elemento mais importante é o movimento; não todo e qualquer movimento, porque o que a determina é a fluência desse movimento (Lange, 1970).

Atualmente convivem no mundo ocidental diversas formas de danças, populares, teatrais, litúrgicas (Gehres, 1995), formas essas que se manifestam na corporificação de gestos imaginados. Dentre os intuitos da dança está o comunicar-se com o outro, seja com o desconhecido, como num ritual, ou com o público, quando a dança é enfocada como Arte. Neste último caso ela tem como prioridade ser objeto de apreciação estética.

Com relação às propostas comentadas, a primeira diz respeito à organização da dança em três grupos de conteúdos, os subtextos, os textos e os contextos:

1- Subtextos da dança - compostos pelos estudos de coreologia de Rudolf Laban e por elementos socioafetivos e culturais.

2- Textos da dança - compostos por elementos da improvisação, da composição e dos repertórios de dança (danças populares, como forró, xaxado, ciranda etc., dança de rua, jazz, balé clássico, sapateado, dança flamenca etc.), incluem o próprio aprendizado de suas técnicas.

3- Contextos da dança - buscam gerar a compreensão de que 
este conteúdo está inserido em um meio social e, portanto, exige o conhecimento histórico, musical, cinesiológico, antropológico, anatômico, estético, da crítica de arte, da saúde etc.

Uma segunda proposta diz respeito às danças populares (Gehres, 1996). Para a autora, a dança é definida como "arte do movimento", e a escola como um ambiente de ensino formal "com a função de sistematizar, socializar e universalizar o conhecimento acerca do real, onde a dança popular faz parte deste conhecimento real". Concluindo ela afirma que a dança é um "tema-conteúdo" a ser tratado nas escolas (p. 28). Baseia-se no trabalho de Laban, que elaborou cinco perguntas básicas para o trato com o conhecimento "dança": quem dança? O que dança? Como dança? Onde dança? Com quem dança? Destaca também que é necessário ao professor(a) dominar a forma e o conteúdo da dança para que não apresente "a produção cultural, a visão de mundo, o saber de determinada camada da população de forma distorcida" (p. 28).

Abordando a dança no primeiro ciclo de escolarização, Xarez et al. (1992), baseados nos estudos de Rudolf Laban em seu livro Dança educativa moderna, organizam o trato com o conhecimento "dança" a partir de três vertentes: as formas (elementos técnicos e passos padronizados); a expressão (oposição ao tecnicismo) e as ações (que partem da exploração do movimento como principal substrato da dança). Os autores defendem esta última abordagem, que, segundo eles, no primeiro ciclo servirá de "base sólida e alargada para quem mais tarde vier a enveredar pelo ensino vocacional" (p. 106).

Com base nessas contribuições das propostas sobre o ensino da dança e seus possíveis conteúdos, faremos uma breve reflexão acerca do trato desses conhecimentos dentro da escola e de suas aproximações numa organização curricular através de ciclos de aprendizagem.

\section{AS PROPOSTAS E OS CICLOS DE SISTEMATIZAÇÃO DO CONHECIMENTO}

Esta breve revisão permite observar que grande é o esforço em sistematizar o conteúdo "dança" na escolarização básica, no intuito de ampliar o acesso dos educandos a esse conhecimento. 
Quanto às propostas concordamos até certo ponto com Xarez et al., que defendem a abordagem das ações. Verificamos que, segundo essa abordagem, o movimento é o principal substrato da dança. Vale lembrar, entretanto, que a criança deve sim experimentar, porém esse experimentar tem significado em qualquer contexto social de que participemos. O importante é que ele seja contextualizado, pois o homem é organizado socialmente através de símbolos, na medida em que toda técnica é um ato simbólico que tem eficiência social. Isso é o que o diferencia como homem (Mauss, 1974). Se não for contextualizada, a Educação Física volta a ser pura atividade física, muitas vezes sem clareza para crianças e adultos e para a sociedade.

Esse contextualizar, que no seu dia-a-dia nos apresenta as diferenças socioculturais, faz parte dos princípios da organização em ciclos. Tais princípios são fundamentados na proposta da Educação Física cujo objeto de estudo é a "expressão corporal como linguagem" (Xarez et al., 1992, p. 102). Assim concluímos que a proposta de Portugal encontra-se ultrapassada tanto em relação ao ensino da dança, como em relação à sua organização curricular nos ciclos de aprendizagem. Falta-lhe totalidade, na medida em que ela se apega apenas a um aspecto.

A segunda proposta, por sua vez, mostra-se mais preocupada com os determinantes socioculturais do conhecimento "dança" na escolarização básica quando defende seu trabalho a partir das formas das danças e seus conteúdos. Ou seja, não se limita ao movimento/técnica, mas preocupa-se, especificamente através dos conteúdos, com a realidade cultural abordada dentro dos campos da escola. Dessa forma, os conteúdos não perdem a visão de totalidade. Apresenta ainda as tensões vividas pelas sociedades de classe normalmente desassistidas e afirma que, na proposta de ciclos, observa-se a intenção de diminuir essas desigualdades. Cabe lembrar que os ciclos defendem os princípios de igualdade, inclusão e integralidade.

Chegamos então à primeira proposta (Marques, 1999), que, no nosso entender, parece mais bem sistematizar o conhecimento "dança", levando em consideração os três grupos de conteúdos apresentados. Além disso, no que concerne aos aspectos técnicos e ao 
contexto, aparecem de uma forma mais sistematizada que na segunda proposta. Percebemos o esforço da autora em abordar nas aulas todas as implicações socioculturais que rodeiam a dança nas sociedades.

Entretanto, estando as duas primeiras propostas mais próximas dos princípios defendidos pelo sistema de organização curricular através dos ciclos de sistematização do conhecimento - o que não exclui a última proposta, mas sim a amplia -, ambas podem ser utilizadas nas escolas que aceitem este desafio. Não se pode perder de vista, porém, que tais propostas devem estar associadas à participação compromissada do professor em um projeto político pedagógico; ao apoio técnico à sua formação continuada; ao apoio estrutural ao seu cotidiano escolar e financeiro (ex: turmas não lotadas, o que dificulta o acompanhamento pedagógico); à propensão para o constante estudo multidisciplinar e interdisciplinar; à definição de um projeto histórico individual e coletivo. Tudo isso vem contribuir para o crescimento do aluno, da escola e da sociedade que se encontra em crise.

Concluímos que, quanto ao conteúdo "dança", especificamente no espaço de interface com o campo da Educação Física, podemos trabalhar relações entre a coreologia e as táticas esportivas; entre os textos-danças e os esportes existentes na sociedade, outra forma de expressão corporal. Podemos, também, empregar as relações dos contextos de uso de determinada atividade de dança (para a promoção da saúde, para terapia, por exemplo). O conteúdo "dança" permite ainda confrontar e respeitar os níveis de desenvolvimento motor dos alunos, o que lhe confere uma análise mais ampliada.

Com relação aos ciclos, estes superam a estrutura seriada, cujos princípios baseiam-se na lógica formal. Necessitam de uma estrutura espiralada oriunda da lógica dialética, que, aplicada ao conteúdo "dança" e mais especificamente à proposta de conteúdos de Marques (1999), proporciona ao aluno ampliar seus dados sobre esse conhecimento (constatando, interpretando, compreendendo até explicar a realidade "dança").

Acreditamos, sim, ser possível a organização em ciclos e o trabalho do professor dentro dessa organização curricular. Para tanto, porém, é necessário o apoio institucional, a conquista diária da 
classe - através de suas instâncias legais - das melhorias almejadas para todos, o compromisso particular e a certeza interior de poder contribuir na formação de homens e mulheres mais solidários, e conseqüentemente de um mundo mais justo.

\title{
Dance in the School Cycles: Theoretical Approaches
}

\begin{abstract}
This study aims at starting an analysis about Dance and School Cycles, through a biblographical review. We will try to reflect upon this systematization from the theoretical reference that best organizes this body of knowledge, which is, in our view, the pedagocial approach of School Physical Education, which is proposed by Soares et all (1992). We also intend to analyze school dance projects suggested by Marques (1999), Gehres (1996) and Xarez et all (1992), and try to establish a reflection upon this content through an amplified approach that comes closer to the systematization in learning cycles, highlighting possibilites of achievements and overcoming of difficulties.
\end{abstract}

KEY WORDS: School - Dance - Systematization of knowledge.

\section{Danza en los Ciclos de Escolarización: Aproximaciones Teóricas}

\section{RESUMEN}

La propuesta del texto es iniciar un análisis, sobre el contenido Danza y los ciclos de escolarización la luz de una revisión bibliográfica. Buscaremos reflexionar sobre esta sistematización a partir de la referencia teórica que mejor organice, desde nuestro punto de vista, el trato pedagógico de la Educación Física Escolar, que es la propuesta de Soares et all (1992), como también analizar propuestas de la danza en la escuela sugerida por Marques (1999), Gehres (1996) y Xarez et all (1992), intentando trazar una reflexión acerca de este contenido en un abordaje que amplíe y se aproxime más de la sistematización en ciclos de conocimiento, destacando posibilidades de conquistas y dificultades.

PALABRAS CLAVES: Escuela - Danza - Ciclos de sistematización del conocimiento.

\section{REFERÊNCIAS}

GEHRES, Adriana de Faria. A dança como arte. Textos para discussão com as turmas de Dança I do curso de licenciatura em Educação Física da ESEF/UPE, 1995.

GEHRES, Adriana de Faria. A dança popular na pré-escola e no primeiro grau menor. Córporis - Revista da Escola Superior de Educação Física da UPE, ano 1, v. 1, n. 1, p. 23-31, jul./dez. 1996. 
LANGE, Roderyk. The nature of dance. The Laban Art of Moviment Guild Magazine. Surrey, maio 1970. Texto traduzido para discussão com as turmas de Dança I do curso de licenciatura em Educação Física da ESEF/UPE, 1995.

MARQUES, Isabel A. Ensino de dança hoje: textos e contextos. São Paulo: Cortez, 1999.

MAUSS, Marcel. Sociologia e antropologia. São Paulo: EPU, 1974. v. 2.

SOARES, Carmem Lúcia et al. Metodologia do ensino da Educação Física. São Paulo: Cortez, 1992.

RECIFE. Prefeitura Municipal. Estudos intensivos/ciclos de aprendizagem e organização escolar, fev. 2002.

XAREZ, Luiz et al. Boletim SPEF: a Dança no $1^{\circ}$ Ciclo do Ensino Básico, Faculdade de Motricidade Humana (UTL), n. 5/6, p. 97106, verão/outono de 1992.

Recebido: maio de 2003

Aprovado: junho de 2003

Endereço para correspondência

Gina Guimarães

Rua Aracatu, 401C, Bloco 1, Ap. 303 Jardim Piedade

Jaboatão dos Guararapes - PE

CEP: 54410-470 
